\title{
Impact of Climatic Factors on Albacore Tuna Thunnus allalunga in the South Pacific Ocean
}

\author{
Ashneel Ajay Singh ${ }^{1,2}$, Kazumi Sakuramoto ${ }^{*}$, Naoki Suzuki1 \\ ${ }^{1}$ Department of Ocean Science and Technology, Tokyo University of Marine Science and Technology, Tokyo, \\ Japan \\ ${ }^{2}$ Department of Fisheries, College of Agriculture, Fisheries and Forestry, Fiji National University, Nasinu, Fiji \\ Email: ajaymsp1@gmail.com, ${ }^{*}$ sakurak@kaiyodai.ac.jp, naoki@kaiyodai.ac.jp
}

Received 14 May 2015; accepted 14 August 2015; published 17 August 2015

Copyright (C) 2015 by authors and Scientific Research Publishing Inc.

This work is licensed under the Creative Commons Attribution International License (CC BY).

http://creativecommons.org/licenses/by/4.0/

(c) () Open Access

\begin{abstract}
Over the years there has been growing interest regarding the effects of climatic variations on marine biodiversity. The exclusive economic zones of South Pacific Islands and territories are home to major international exploitable stocks of albacore tuna (Thunnus alalunga); however the impact of climatic variations on these stocks is not fully understood. This study was aimed at determining the climatic variables which have impact on the time series stock fluctuation pattern of albacore tuna stock in the Eastern and Western South Pacific Ocean which was divided into three zones. The relationship of the climatic variables for the global mean land and ocean temperature index (LOTI), the Pacific warm pool index (PWI) and the Pacific decadal oscillation (PDO) was investigated against the albacore tuna catch per unit effort (CPUE) time series in Zone 1, Zone 2 and Zone 3 of the South Pacific Ocean from 1957 to 2008. From the results it was observed that LOTI, PWI and PDO at different lag periods exhibited significant correlation with albacore tuna CPUE for all three areas. LOTI, PWI and PDO were used as independent variables to develop suitable stock reproduction models for the trajectory of albacore tuna CPUE in Zone 1, Zone 2 and Zone 3. Model selection was based on Akaike Information Criterion (AIC), $R^{2}$ values and significant parameter estimates at $p<0.05$. The final models for albacore tuna CPUE in all three zones incorporated all three independent variables of LOTI, PWI and PDO. From the findings it can be said that the climatic conditions of LOTI, PWI and PDO play significant roles in structuring the stock dynamics of the albacore tuna in the Eastern and Western South Pacific Ocean. It is imperative to take these factors into account when making management decisions for albacore tuna in these areas.
\end{abstract}

\section{Keywords}

Albacore Tuna, Thunnus alalunga, Global Mean Land and Ocean Temperature Index, Pacific Warm Pool Index, Pacific Decadal Oscillation, Catch per Unit Effort

\footnotetext{
${ }^{*}$ Corresponding author.
}

How to cite this paper: Singh, A.A., Sakuramoto, K. and Suzuki, N. (2015) Impact of Climatic Factors on Albacore Tuna Thunnus alalunga in the South Pacific Ocean. American Journal of Climate Change, 4, 295-312. 


\section{Introduction}

In the Pacific Ocean, the most dominant fishery can be said to be tuna fisheries which include albacore (Thunnus alalunga), yellowfin (Thunnus albacores), bigeye (Thunnus obesus) and skipjack (Katsuwonus pelamis) tuna species that represent $>90 \%$ of the total global tuna harvests [1]. The exclusive economic zone (EEZ) of the Pacific Island countries and territories (PICTs) within the Western and Central Pacific Convention Area (WCPCA) between $\sim 25^{\circ} \mathrm{N}$ to $25^{\circ} \mathrm{S}$ and $130^{\circ} \mathrm{E}$ to $130^{\circ} \mathrm{W}$ has a coverage area of $>27$ million $\cdot \mathrm{km}^{2}$ and the economy and food security of most of these PICTs are heavily dependent on oceanic fisheries activities [2]-[4]. Albacore tuna is substantially distributed within the WCPCA and has contributed to $~ 6 \%$ of the global tuna catch in recent years [5]-[7]. In the Western and Central Pacific Ocean in recent years the total annual catch of albacore tuna has been $\sim 126,000$ tonnes with a value of USD 342 million. About 50\% of these catches originate from the EEZs of PICTs [2].

Albacore tuna (Thunnus alalunga) is a commercially important species of tuna to the economy of various countries in the WCPCA in the South Pacific [8] [9]. They are also highly migratory with sexual maturity, age, season and their catch varies both seasonally and spatially [10]-[12]. Albacore tuna fisheries have expanded considerably in the South Pacific Ocean with almost three-fold increase in catch compared with the past two decades from 1990 to 2010 [13]. Even though there has been a long history of albacore tuna fisheries in the Pacific Ocean, their ecological characteristics are not sufficiently understood.

The significant role of climatic conditions in structuring the time series trajectory, spatial distribution and biological processes relating to tuna species has been shown previously in [14]. In the Pacific Ocean the projected distribution of yellowfin, skipjack and bigeye tuna within the $21^{\text {st }}$ century likely shifts towards the East in response to alterations in the warm pool and the Pacific Equatorial Divergence [14]-[16]. Singh [17] showed that the time series stock trajectory of yellowfin tuna in the Eastern and Western South Pacific was significantly influenced by the climatic conditions of Pacific warm pool index (PWI), global mean land and ocean temperature index (LOTI) and Southern oscillation index (SOI). Polovina [12] studied the movement of albacore tuna in relation to the movement of the transition zone chlorophyll front in the North Pacific. Albacore tuna stock was shown to follow this chlorophyll front movement which was substantially correlated with El Niño and La Niña events. The relationship of albacore tuna to El Niño and La Niña events has also been shown in [18] and [19] where albacore shows low recruitment during El Niño and high during La Niña events. Albacore tuna recruitment in the Pacific has been shown to be correlated to the climatic indices of El Niño Southern Oscillation (ENSO) and Pacific Decadal Oscillation [18]. Dufour [20] studied the feeding migration of albacore tuna from 1967 to 2005 in the Bay of Biscay in relation to climatic variables. Results showed significant relationship of the albacore tuna to the climatic variables of North Atlantic Oscillation and Northern Hemisphere Temperature Anomaly. It was also shown that long-time scales are necessary to detect relationships with environmental and climatic variables.

In the Pacific Ocean the albacore spawning stock and fishing effort are still within sustainable levels; however during the lifespan of the recorded fishery, the stock by weight has gradually declined and in recent years catches have continued to increase with increasing effort [21]. In many cases fisheries management decisions for most fisheries are primarily based on implementing adjustment to the fishing pressure and related activities. While this may work for some fisheries and over short periods of time, the concept cannot be generalized across different species and different areas of the globe. Each fishery by species and location is affected by biotic and abiotic factors in different ways. The extent to which these factors impact a fishery differs significantly, making it fundamental to understand the role of the intrinsic and extrinsic factors affecting the underlying trajectory of a fish stock in order to effectively manage the fishery. The objective of this study is to elucidate which climatic conditions are related to the stock trajectory of the albacore tuna in the Eastern and Western South Pacific Ocean and to what degree. The climatic variables that exhibit sufficient correlation to albacore tuna stocks shall be incorporated into models with the aim of attempting to significantly reconstruct the stock dynamics of albacore tuna in the designated areas.

\section{Materials and Methods}

\subsection{Data}

The commission members and cooperating non-members of the Western and Central Pacific Fisheries Commission (WCPFC) provide aggregate, operational and annual tuna catch and effort estimates which the WCPFC 
uses to compile a public domain version (https://www.wcpfc.int/) of the aggregated catch and effort data. The catch and effort data on albacore tuna (T. alalunga) in the Eastern and Western South Pacific from 1957 to 2008 was obtained from the WCPFC public domain data. The stock distribution of albacore tuna data used for this study is shown in Figure 1.

The albacore tuna data from longline was selected over pole and line and purse seine data as the longline data was most extensive [21] by time series and the effort was available as the number of hooks which reduced the possibility and extent of observation errors. Also, due to the difference in the type of effort data, pole and line and purse seine data could not be used together with longline data. Monthly summaries of catch numbers, total weights and total number of hooks were georeferenced in $5^{\circ}$ longitude and latitude grids and separated into three areas; Zone $1\left(2.5^{\circ} \mathrm{N}-47.5^{\circ} \mathrm{S}, 162.5^{\circ} \mathrm{W}-152.5^{\circ} \mathrm{W}, 7.5^{\circ} \mathrm{S}-47.5^{\circ} \mathrm{S}, 152.5^{\circ} \mathrm{W}-132.5^{\circ} \mathrm{W}\right)$, Zone $2\left(2.5^{\circ} \mathrm{N}-47.5^{\circ} \mathrm{S}\right.$, $\left.172.5^{\circ} \mathrm{E}-162.5^{\circ} \mathrm{W}\right)$ and Zone $3\left(2.5^{\circ} \mathrm{N}-47.5^{\circ} \mathrm{S}, 147.5^{\circ} \mathrm{E}-172.5^{\circ} \mathrm{E}\right)$ (Figure 1). Annual albacore tuna catch and effort was calculated from aggregated longline monthly data by geographical coordinates for Zone 1, Zone 2 and Zone 3. The catch per unit effort (CPUE) was calculated from the catch and effort data for the three areas with the catch data being in tonnes and effort as the number of hooks (Figures 2(a)-(c)). It was important to treat albacore tuna data for Zone 1, Zone 2 and Zone 3 as three different stocks as the total area was too large for any one stock and exploratory analysis showed differences in the catch and CPUE patterns and magnitudes as well as catch and effort relationships for the three areas.

In Figure 2(a) the fluctuation pattern for the albacore tuna CPUE time series in Zone 1 for the years 1957 to 2008 can be seen. There is an increasing trend for the years 1957-1960, 1964-1966, 1972-1974 1975-1978, 1981-1983, 1984-1986, 1990-1992, 1995-1998, and 2000-2002 and from 1960-1964, 1966-1969, 1970-1972, 1986-1990, 1992-1995, 1998-2000 and 2002-2004 a decreasing trend can be observed with the highest peak in 1960 and the lowest point in 1995. CPUE is distinctively high from 1958-1962 with a sharp decline from 19601964. For Zone 2 (Figure 2(b)) the trajectory of albacore tuna has an increasing trend for the years 1965-1967, 1974-1976, 1979-1981, 1984-1986, 1989-1991, 1995-1997 and 2004-2006 with a decreasing trend for the years 1967-1974, 1991-1993, 1997-2000, 2001-2004 and 2006-2008. The CPUE is at its highest peak in 1962 with sharp declines from 1960-1963 and 1967-1974 and the lowest values in 1974, 1979, 1982, 1984 and 1989. Figure 2(c) shows the trajectory of albacore tuna in Zone 3 where an increasing trend can be observed from 1957-1959, 1968-1970, 1976-1978, 1996-1998, 2003-2006 with a decreasing trend from 1961-1964, 1970-1972, 1978-1982, 1983-1985 and 1986-1990. The highest peaks can be observed in 1959 and 1970 with sharp declines from 1959 to 1964 and 1970 to 1974. Zone 1 and Zone 2 CPUE trajectory for albacore tuna have more similarities compared with Zone 3 which is more chaotic in contrast.

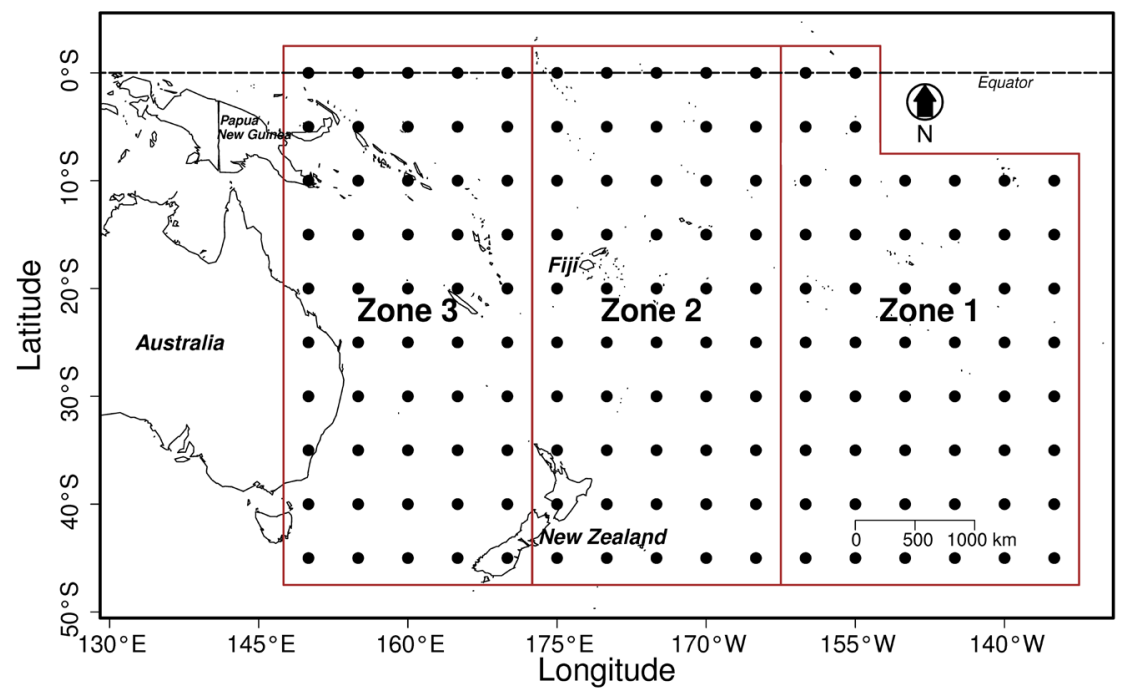

Figure 1. Map showing the stock distribution of the albacore tuna (T. alalunga) in the Eastern and Western South Pacific Ocean. The study area was divided into Zone 1, Zone 2 and Zone 3 shown by the enclosure polygons and the black circles represent the data distribution in $5^{\circ}$ by $5^{\circ}$ geographical grids. 


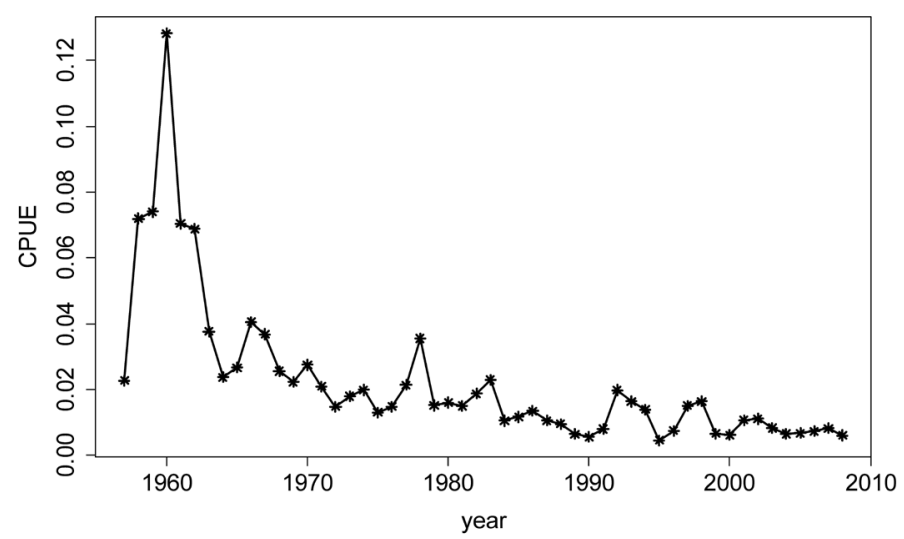

(a)

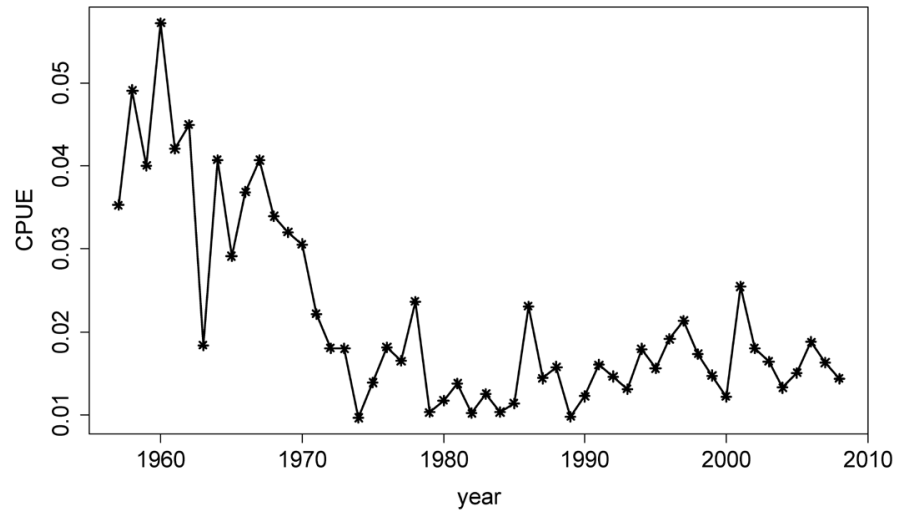

(b)

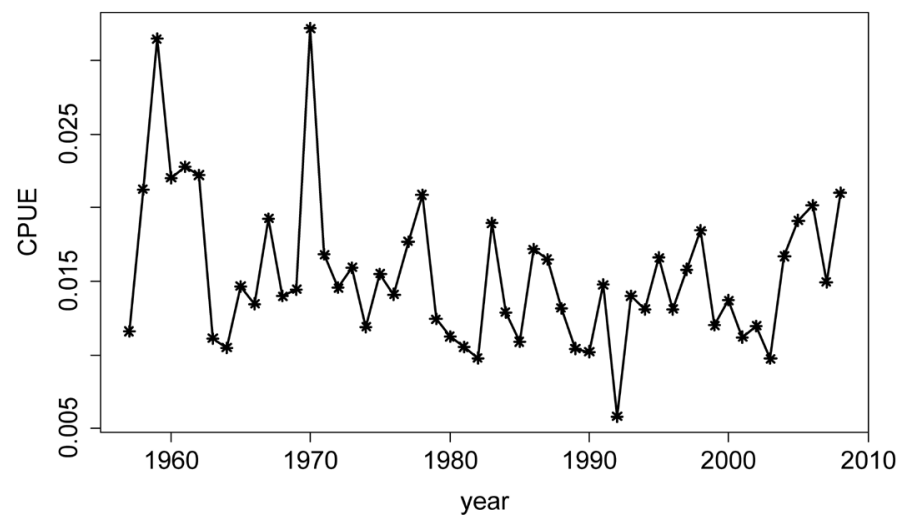

(c)

Figure 2. (a) The CPUE time series trajectory of the albacore tuna ( $T$. alalunga) stock in Zone 1 for the years ranging from 1957-2008; (b) The CPUE time series trajectory of the albacore tuna (T. alalunga) stock in Zone 2 for the years ranging from 1957-2008; (c) The CPUE time series trajectory of the albacore tuna (T. alalunga) stock in Zone 3 for the years ranging from 1957-2008.

The climatic data for the global mean land and ocean temperature index (LOTI) for the latitude band $44^{\circ} \mathrm{S}$ to $64^{\circ} \mathrm{S}$ was obtained from the National Aeronautics and Space Administration (NASA), Goddard Institute for Space studies, Goddard Space Flight Center, Science and Exploration Directorate, Earth Science Division (http://data.giss.nasa.gov/gistemp) from 1952 to 2008. The LOTI data was calculated on monthly basis by combining and using data files from National Oceanic and Atmospheric Administration (NOAA) Global Historical 
Climatology Network v3 for meteorological stations, Extended Reconstructed Sea Surface Temperature for ocean areas and Scientific Committee on Antarctic Research for Antarctic stations as outlined in [22]. The calculated monthly data on Pacific warm pool index (PWI) and Pacific decadal oscillation (PDO) was obtained from NOAA, Earth System Research Laboratory, Physical Sciences Division (http://www.esrl.noaa.gov) from 1952 to 2008.

\subsection{Exploratory Analysis and Unit Root Test}

Regression analysis was applied to identify if relationships existed between the dependent variables of albacore tuna CPUE in Zone $1\left(Y_{z 1}\right)$, Zone $2\left(Y_{z 2}\right)$ and Zone $3\left(Y_{z 3}\right)$ against the climatic independent variables of LOTI $(L)$, PWI $(P)$ and PDO $(O)$. Monthly and annual $L, P$ and $O$ were tested against $Y_{z 1}, Y_{z 2}$, and $Y_{z 3}$ at $t-n$ years where $n=0,1, \cdots, 5$ since the age of most of the stock harvested in the Pacific Ocean ranges between $2-4$ years old [23]-[25]. Results with $p<0.05$ were considered as significant relationships. To avoid violations of assumptions from the statistical techniques utilized, the protocol for data exploration was followed as in [26]. As outlined in [26], all selected variables were tested for the presence of outliers using scatterplots and boxplots as well as for correlations among independent variables. Results with coefficient of correlation with $R>0.500$ were considered as significant.

When certain variations in a time series has transient effects and does not permanently alter the trend of the time series, the trend is classified as being stationary. When variations or shocks permanently alter the time series, the trend is classified as stochastic and having a unit root. The presence of a unit root in a time series can result in specious correlations among variables [27] [28]. The independent variables which exhibited significant correlation with the dependent variables as well as the albacore tuna CPUE in Zone 1, Zone 2 and Zone 3 were analyzed to confirm whether any of the time series data were a non-stationary process with the Augmented Dickey-Fuller and MacKinnons unit root test [27]-[29].

\subsection{Stock Reproduction Model}

Independent variables which exhibited significant relationship at $p<0.05$ and had lowest AIC values with albacore tuna CPUE from exploratory analysis for each climatic condition were incorporated in the development of stock reproduction models of the albacore tuna CPUE in the South Pacific Zone 1, Zone 2 and Zone 3. The objective was to construct a stock reproduction model which can reconstruct the albacore tuna CPUE trajectory using climatic data as independent variables at $p<0.05$. The Generalized Linear Model (GLM) was used as parent formula for the stock reproduction model for $Y_{z 1}, Y_{z 2}$ and $Y_{z 3}$ as shown in Equation (1)

$$
\ln \left(Y_{z i, t}\right)=\ln \left(\alpha_{0}\right)+\alpha_{1, n} s_{1, t-n}+\alpha_{2, n} s_{2, t-n}+\cdots+\alpha_{k, n} s_{k, t-n}+\varepsilon_{z i, t}
$$

where $Y_{z i, t}$ is the CPUE of albacore tuna in the South Pacific region, $z$ is the distribution zone with $i=1,2,3, \alpha_{0}$ is the parameter for the intercept, $\alpha_{1}, \alpha_{2}, \cdots, \alpha_{k}$ are parameter estimates, $s_{1}, s_{2}, \cdots, s_{k}$ are the independent climatic variables with $k=1,2$ and $3, t$ is the year with $n=0,1, \cdots, 5$ and $\varepsilon_{z i, t}$ is an unsolved normally distributed random variable.

The response surface methodology (RSM) is a set of statistical and mathematical techniques which uses linear and polynomial functions to incorporate independent variables into mathematical and statistical models to describe a system or data which is under study [30]-[33]. RSM was used to transform Equation (1) by incorporation of second and third order polynomials to determine if variables could be better fit with this technique in Equation (2)

$$
\ln \left(Y_{z i, t}\right)=\ln \left(\alpha_{0}\right)+\alpha_{1, q, n} s_{1, t-n}^{q}+\alpha_{2, q, n} s_{2, q, n}^{q}+\cdots+\alpha_{k, q, n} s_{k, t-n}^{q}+\varepsilon_{z i, t}
$$

where $q=1,2$ and 3. Log transformation of the dependent variable and y-intercept were done to reduce the effects of outliers and skewness. For Equation (1) and Equation (2), independent variables were investigated in various combinations by successive elimination to identify suitable models for reconstructing the trajectory of the albacore tuna stock in Zone 1, Zone 2 and Zone 3. Tests for the homogeneity of variance for the residuals of the model against the fitted values were performed. The least square estimators would be significantly degraded if the range of variance were $\geq 4.00$ [34]. Akaike Information Criterion (AIC) and $R^{2}$ values at $p<0.05$ were used for model selection criteria [35]. The predicted and referred trajectory of the albacore tuna CPUE in Zone 1, Zone 2 and Zone 3 were plotted and compared. The statistical software "R", version 3.0.1 was used to perform 
all statistical analysis for this study [36].

\section{Results}

\subsection{Catch and Effort Trajectory}

From Figure 3 the catch and effort for albacore tuna in the South Pacific Zone 1, Zone 2 and Zone 3 show similar trajectory patterns. The linear relationship of the albacore tuna catch and effort in all three areas are shown in Figure 4. The points below the slope mostly refer to the years where the CPUE was low and the points above the slope mostly refer to the years where the CPUE high. In Figure 4, the further (closer) the points disperse from the slope, the lower (higher) the correlation between the catch and effort. For Zone 2 and Zone 3 the catch and effort correlate strongly with most of the points lying close to the slope line. For Zone 1, the relationship of the effort although significant, is much weaker in comparison to Zone 2 and Zone 3 . The determination coefficients for Zone 1, Zone 2 and Zone 3 are 0.544, 0.786 and 0.884 respectively which makes it evident that the catch dynamics of albacore tuna in Zone 1, Zone 2 and Zone 3 are influenced significantly at varying degrees by the fishing effort which makes the catch trend unsuitable for trend analysis. For this study we decided to use the CPUE as it standardizes the effort with reference to catch and is a more suitable representative of the albacore tuna stock dynamics which will enable better trend analysis and determination of relationships with independent variables.
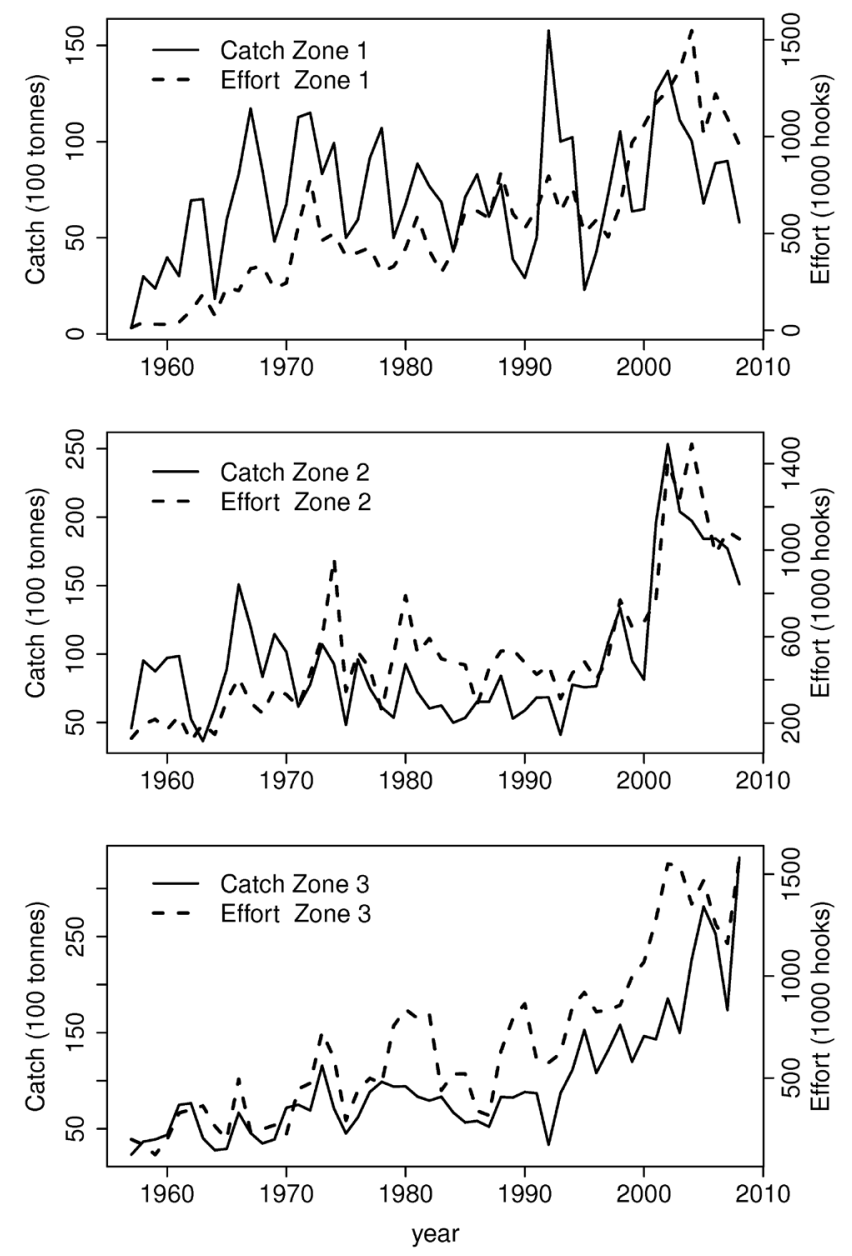

Figure 3. The catch and effort time series trajectory of the albacore tuna (T. alalunga) stock in Zone 1, Zone 2 and Zone 3 from 1957-2008. The similarities and differences in the time series patterns can be observed. 

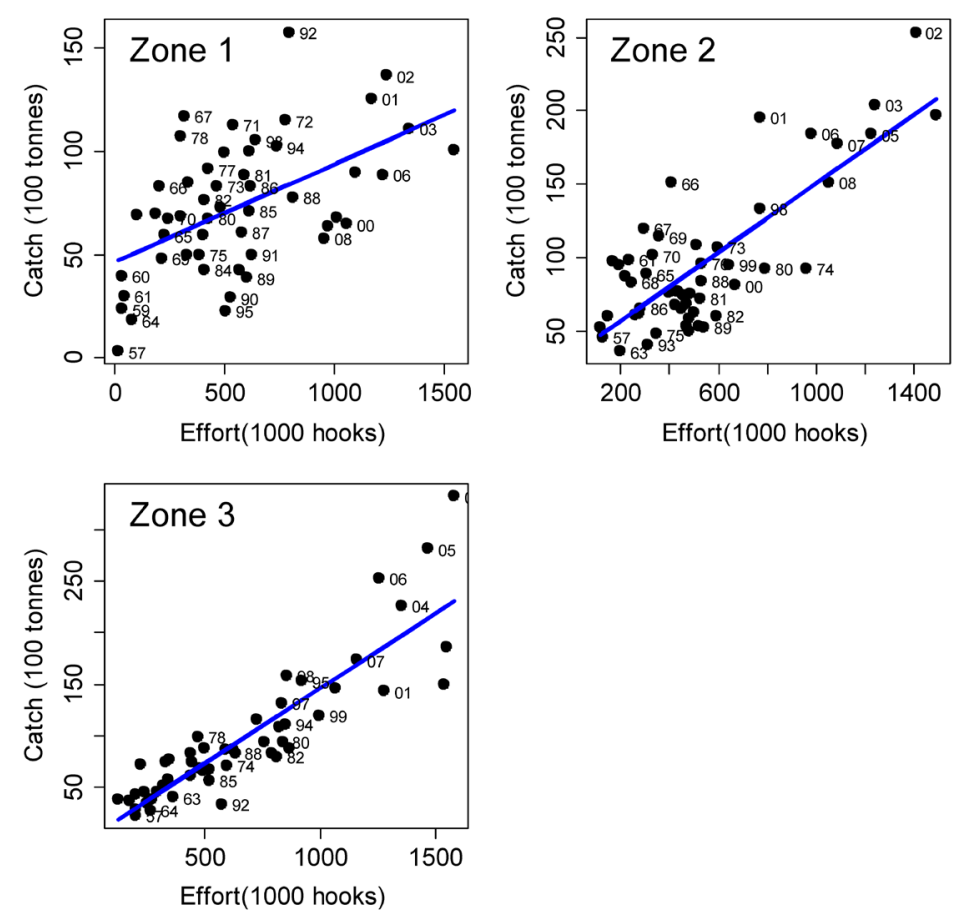

Figure 4. The relationship between the catch and effort for the albacore tuna (T. alalunga) stock in Zone 1, Zone 2 and Zone 3 from 1957-2008. The determination coefficients are $0.544,0.786$ and 0.884 respectively.

In Figure 5 the differences and similarities between the catch and CPUE of albacore tuna in Zone 1, Zone 2 and Zone 3 can be observed. The catch levels fluctuate around similar magnitudes from 1957 to around 2000 and from around the year 2000 the catch levels begin to diverge and by 2008 there is significantly large difference in catch among the three zones with Zone 3 being the largest catch followed by Zone 2 and the least being Zone 1. Between 1958 to 1962, significantly large differences can be observed in the CPUE magnitudes for the three areas with Zone 1 being the largest followed by Zone 2 and the lowest being Zone 3. From around 1970 the CPUE for the three zones becomes synonimous until 2008. Although the catch magnitudes are quite different from around the year 2000 the CPUE for the three zones remains constant.

\subsection{Exploratory Analysis and Unit Root Test}

The results for regression analysis of the albacore tuna CPUE in the South Pacific Zone 1, Zone 2 and Zone 3 against independent variables of climatic conditions for the years $t-n \quad(n=0,1, \cdots, 5)$ are presented in Table 1. The results only include the variables which exhibited highest correlations according to the $R^{2}$ and AIC values at $p<0.05$. LOTI for the latitude band $44^{\circ} \mathrm{S}$ to $64^{\circ} \mathrm{S}(L)$, PWI for the month of February $\left(P_{f}\right)$ and November $\left(P_{n}\right)$ and PDO for the month of February $\left(O_{f}\right)$ and March $\left(O_{m}\right)$ had significant correlations with the dependent variables of $Y_{z 1}, Y_{z 2}$ and $Y_{z 3}$. LOTI exhibited strongest correlation with a lag of $t-1$ year for all three zones with PWI exhibiting most significant correlations at $t-2$ in all three cases with $P_{n}$ for $Y_{z 1}$ and $Y_{z 2}$ and at $P_{f}$ for $Y_{z 3}$. PDO had most significant correlation at $t-4$ for all three zones with $O_{f}$ for $Y_{z 1}$ and $Y_{z 3}$ and $O_{m}$ for $Y_{z 2}$. These independent variables made ecological sense as they geographically relate to the data coverage area for Zone 1 , Zone 2 and Zone 3.

In Figure 6 the boxplots show the spread of the albacore tuna CPUE for Zone 1, Zone 2 and Zone 3 and the climatic variables from Table 1 . Some relatively high values can be observed for the CPUE in the three Zones, especially for Zone 1 where a single high value is way outside the range of the rest of the data. However, these values should not be labeled as outliers without further exploration [26]. To identify whether outliers are present in the CPUE data, scatter plots of the catch and effort data used in the calculation of the CPUE were presented. It can be seen from Figure 6 that the catch and effort values are not unusually large or small. Due to this and the large sets of data that were used to calculate the annual catch and effort, the likelihood of observation and 

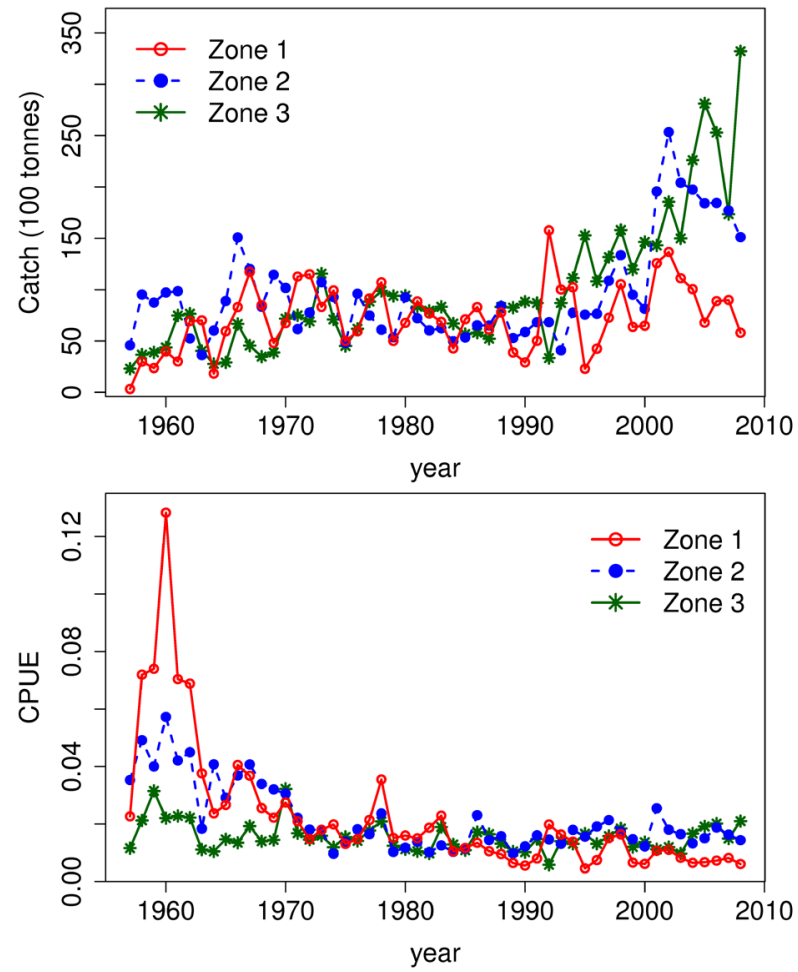

Figure 5. The catch and CPUE time series trajectory of the albacore tuna (T. alalunga) stock in Zone 1, Zone 2 and Zone 3 from 1957 to 2008. Differences can be seen in the recent years for catch and in earlier years for CPUE magnitudes for each zone.
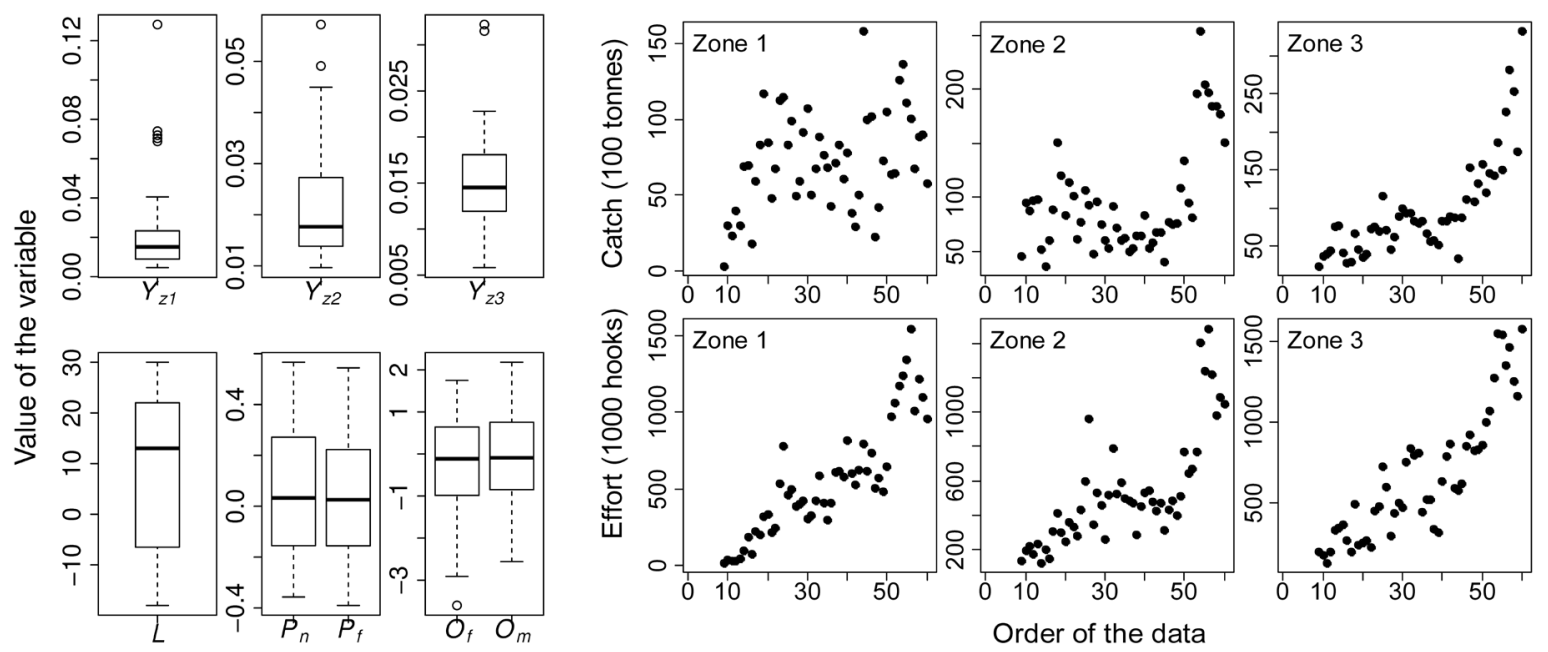

Figure 6. The boxplots for the dependent and independent variables showing the spread of the data with the line in the middle of the boxes representing the median. Scatter plots show the distribution for the catch and effort data for Zone 1 , Zone 2 and Zone 3.

process errors are greatly minimized and it is safe to assume that the CPUE values which extend outside the boxplot range are not outliers but authentic values.

Spurious correlations may sometimes arise when regression analysis is used. Unit root test which is a statistical method to identify cases of unauthentic correlations [27]-[29] was performed for all the time series data used in this study. Table 2 shows the results for MacKinnon's test (M-test) and Augmented Dickey-Fuller test (ADF-test). Time-series have a stationary process if they exhibit t-test value (t-value) $<0$ at $p<0.05$. The tests 
Table 1. Results for regression analysis of albacore tuna (T. alalunga) stock in the South Pacific Ocean Zone 1, Zone 2 and Zone 3 against independent climate variables. Variables exhibiting values with $p<0.05$ are significant.

\begin{tabular}{|c|c|c|c|c|c|c|c|c|c|}
\hline \multirow{3}{*}{ Year } & \multicolumn{9}{|c|}{ Zone 1} \\
\hline & \multicolumn{3}{|c|}{$Y_{z 1}, L$} & \multicolumn{3}{|c|}{$Y_{z 1}, P_{n}$} & \multicolumn{3}{|c|}{$Y_{z 1}, O_{f}$} \\
\hline & $R^{2}$ & $p$-value & AIC & $R^{2}$ & $p$-value & AIC & $R^{2}$ & $p$-value & AIC \\
\hline$t$ & 0.388 & $8.08 \times 10^{-7}$ & -266 & 0.258 & $1.23 \times 10^{-4}$ & -256 & $9.19 \times 10^{-5}$ & $9.46 \times 10^{-1}$ & -241 \\
\hline$t-1$ & 0.434 & $1.08 \times 10^{-7}$ & -270 & 0.283 & $4.89 \times 10^{-5}$ & -258 & 0.016 & $3.75 \times 10^{-1}$ & -242 \\
\hline$t-2$ & 0.376 & $1.32 \times 10^{-6}$ & -265 & 0.307 & $2.07 \times 10^{-5}$ & -260 & 0.054 & $9.78 \times 10^{-2}$ & -244 \\
\hline$t-3$ & 0.365 & $2.15 \times 10^{-6}$ & -264 & 0.278 & $5.99 \times 10^{-5}$ & -258 & 0.118 & $1.26 \times 10^{-2}$ & -247 \\
\hline$t-4$ & 0.290 & $3.89 \times 10^{-5}$ & -259 & 0.287 & $4.31 \times 10^{-5}$ & -258 & 0.230 & $3.26 \times 10^{-4}$ & -254 \\
\hline$t-5$ & 0.331 & $8.02 \times 10^{-6}$ & -262 & 0.301 & $2.59 \times 10^{-5}$ & -259 & 0.148 & $4.86 \times 10^{-3}$ & -249 \\
\hline \multicolumn{10}{|c|}{ Zone 2} \\
\hline & \multicolumn{3}{|c|}{$Y_{z 2}, L$} & \multicolumn{3}{|c|}{$Y_{z 2}, P_{n}$} & \multicolumn{3}{|c|}{$Y_{22}, O_{m}$} \\
\hline$t$ & 0.518 & $2.05 \times 10^{-9}$ & -349 & 0.234 & $2.83 \times 10^{-4}$ & -325 & 0.095 & $2.65 \times 10^{-2}$ & -316 \\
\hline$t-1$ & 0.566 & $1.30 \times 10^{-10}$ & -355 & 0.232 & $3.00 \times 10^{-4}$ & -325 & 0.140 & $6.40 \times 10^{-3}$ & -319 \\
\hline$t-2$ & 0.524 & $1.30 \times 10^{-9}$ & -350 & 0.275 & $6.56 \times 10^{-5}$ & -328 & 0.216 & $5.16 \times 10^{-4}$ & -324 \\
\hline$t-3$ & 0.547 & $3.71 \times 10^{-10}$ & -352 & 0.253 & $1.43 \times 10^{-4}$ & -326 & 0.134 & $7.65 \times 10^{-3}$ & -319 \\
\hline$t-4$ & 0.459 & $3.41 \times 10^{-8}$ & -343 & 0.253 & $1.46 \times 10^{-4}$ & -326 & 0.226 & $3.67 \times 10^{-4}$ & -325 \\
\hline$t-5$ & 0.450 & $5.27 \times 10^{-8}$ & -342 & 0.208 & $6.87 \times 10^{-4}$ & -323 & 0.213 & $5.72 \times 10^{-4}$ & -324 \\
\hline \multicolumn{10}{|c|}{ Zone 3} \\
\hline & \multicolumn{3}{|c|}{$Y_{z 3}, L$} & \multicolumn{3}{|c|}{$Y_{z 3}, P_{f}$} & \multicolumn{3}{|c|}{$Y_{z 3}, O_{f}$} \\
\hline$t$ & 0.118 & $1.27 \times 10^{-2}$ & -404 & 0.002 & $7.28 \times 10^{-1}$ & -398 & 0.006 & $5.81 \times 10^{-1}$ & -398 \\
\hline$t-1$ & 0.144 & $5.53 \times 10^{-3}$ & -406 & 0.005 & $6.31 \times 10^{-1}$ & -398 & 0.004 & $6.49 \times 10^{-1}$ & -398 \\
\hline$t-2$ & 0.095 & $2.60 \times 10^{-2}$ & -403 & 0.094 & $2.69 \times 10^{-2}$ & -403 & 0.015 & $3.85 \times 10^{-1}$ & -398 \\
\hline$t-3$ & 0.085 & $3.62 \times 10^{-2}$ & -402 & 0.042 & $1.45 \times 10^{-1}$ & -400 & 0.028 & $2.39 \times 10^{-1}$ & -399 \\
\hline$t-4$ & 0.117 & $1.29 \times 10^{-2}$ & -404 & 0.031 & $2.11 \times 10^{-1}$ & -399 & 0.152 & $4.35 \times 10^{-3}$ & -406 \\
\hline$t-5$ & 0.109 & $1.71 \times 10^{-2}$ & -404 & 0.011 & $4.55 \times 10^{-1}$ & -398 & 0.141 & $6.01 \times 10^{-3}$ & -406 \\
\hline
\end{tabular}

Table 2. Results of unit root tests for dependent and independent variables used in regression analysis from Table 1.

\begin{tabular}{|c|c|c|c|c|}
\hline \multirow{2}{*}{ Series } & \multicolumn{2}{|c|}{ M-test } & \multicolumn{2}{|c|}{ ADF-test } \\
\hline & t-value & $p$-value & t-value & $p$-value \\
\hline$Y_{z 1} 1957-2008$ & -7.698 & $6.32 \times 10^{-10}$ & -7.698 & $<1.00 \times 10^{-2}$ \\
\hline$Y_{z 2} 1957-2008$ & -11.795 & $8.69 \times 10^{-16}$ & -11.795 & $<1.00 \times 10^{-2}$ \\
\hline$Y_{z 3} 1957-2008$ & -10.531 & $4.53 \times 10^{-14}$ & -10.531 & $<1.00 \times 10^{-2}$ \\
\hline L 1949-2008 & -10.655 & $4.37 \times 10^{-15}$ & -10.655 & $<1.00 \times 10^{-2}$ \\
\hline$P_{n} 1949-2008$ & -10.750 & $3.12 \times 10^{-15}$ & -10.750 & $<1.00 \times 10^{-2}$ \\
\hline$P_{f} 1949-2008$ & -13.030 & $<2.20 \times 10^{-16}$ & -13.025 & $<1.00 \times 10^{-2}$ \\
\hline$O_{f} 1949-2008$ & -11.161 & $7.36 \times 10^{-16}$ & -11.161 & $<1.00 \times 10^{-2}$ \\
\hline$O_{m} 1949-2008$ & -11.345 & $3.88 \times 10^{-16}$ & -11.345 & $<1.00 \times 10^{-2}$ \\
\hline
\end{tabular}


showed that all the variables showed stationarity and did not have a unit root process and the relationships presented in Table 1 are non-spurious.

\subsection{Stock Reproduction Model}

Table 3 shows the results of incorporating the independent climatic variables from Table 1 into stock reproduction models for the CPUE of the albacore tuna in the South Pacific Zone 1, Zone 2 and Zone 3. Models with highest $R^{2}$ and lowest AIC values at $p<0.05$ are shown for each zone. Model (a) had the highest $R^{2}$ and lowest AIC value for albacore tuna in Zone 1 which incorporates the variables $L_{t-1}, P_{n, t-2}$ and $O_{f, t-4}$. For the albacore tuna in Zone 2 model (d) was the most suitable according to the highest $R^{2}$ and lowest AIC value which incorporated the variables $L_{t-1}, P_{n, t-2}$ and $O_{m, t-4}$. For Zone 3, model (g) is the most suitable and it incorporates the independent variables $L_{t-1}, P_{f, t-2}$ and $O_{f, t-4}$ (Table 3 ).

There were no significantly high correlations observed for the collinearity tests among the independent variables incorporated into the models in Table 3. According to the results of homogeneity tests all model residuals shown in Table 3 have a variance of $<0.09$ as shown in Figure 7 which fulfilled the requirements of homogeneity where in order for the least square estimators to be reliable the variance needs to be $<4.00$ [34].

The plot of Zone 1 albacore tuna CPUE and the estimated CPUE trajectory from model (a) (Table 3) can be seen in Figure 8. Similarly the plot of the referred and forecasted CPUE of the albacore tuna in Zone 2 from model (d) can be seen in Figure 9. For Zone 3 the albacore predicted CPUE from model (g) and referred CPUE can be seen in Figure 10. For Zone 1 and Zone 2 the referred CPUE has strong fitness with the predicted CPUE compared to Zone 3 where although significant, the predicted CPUE has much weaker fitness with referred CPUE. Figure 11 shows the linear correlations of the referred and predicted albacore tuna CPUE in Zone 1, Zone 2 and Zone 3 from the models presented in Table 3. For models (a), (d) and (g) the determination coefficients of the referred CPUE to the CPUE predicted (Table 3, Figure 11) are 0.889, 0.884 and 0.453 respectively. For Figure 11(a) the slope is 1.431 with 95\% confidence interval of $(1.222,1.641)$, for Figure 11(d) the slope is 1.027 with $95 \%$ confidence interval of $(0.873,1.182)$ and for Figure $11(\mathrm{~g})$ the slope is 1.123 with $95 \%$ confidence interval of $(0.494,1.752)$. These values show that the slopes in all three cases are either close to or not significantly different from unity which as indication of significant impact of the independent variables on the

Table 3. Stock reproduction models and some parameters using the independent variables $L, P$ and $O$ from Table 1 for the albacore tuna (T. alalunga) stock in the South Pacific Ocean Zone 1, Zone 2 and Zone 3. Values are only shown for statistically most significant models at $p<0.05$.

\begin{tabular}{|c|c|c|c|c|c|}
\hline \multicolumn{6}{|c|}{ Zone 1} \\
\hline & Model & $R^{2}$ & $\mathrm{t}$-value & $p$-value & AIC \\
\hline 1) & $\ln \left(Y_{z 1, t}\right)=-3.83-2.25 \times 10^{-2} \times L_{t-1}-1.50 \times P_{n, t-2}+8.03 \times 10^{-2} \times O_{f, t-4}^{2}$ & 0.791 & 13.748 & $<2.20 \times 10^{-16}$ & -322 \\
\hline 2) & $\ln \left(Y_{z 1, t}\right)=-3.78-2.06 \times 10^{-2} \times L_{t-1}-1.37 \times P_{n, t-2}-3.49 \times 10^{-2} \times O_{f, t-4}^{3}$ & 0.787 & 13.580 & $<2.20 \times 10^{-16}$ & -321 \\
\hline 3) & $\ln \left(Y_{z 1, t}\right)=-3.97-5.06 \times 10^{-2} \times L_{t-1}+1.56 \times 10^{-3} \times L_{t-1}^{2}-4.26 \times P_{n, t-2}^{3}-0.129 \times O_{f, t-4}$ & 0.751 & 12.287 & $<2.20 \times 10^{-16}$ & -313 \\
\hline \multicolumn{6}{|c|}{ Zone 2} \\
\hline 4) & $\ln \left(Y_{z 2, t}\right)=-3.89-3.17 \times 10^{-2} \times L_{t-1}+7.82 \times 10^{-4} \times L_{t-1}^{2}-0.754 \times O_{m, t-4}+1.69 \times P_{n, t-2}^{2}$ & 0.781 & 13.358 & $<2.20 \times 10^{-16}$ & -390 \\
\hline 5) & $\ln \left(Y_{z 2, t}\right)=-3.79-3.58 \times 10^{-2} \times L_{t-1}+2.86 \times 10^{-5} \times L_{t-1}^{3}-0.669 \times O_{m, t-4}+1.76 \times P_{n, t-2}^{2}$ & 0.766 & 12.779 & $<2.20 \times 10^{-16}$ & -387 \\
\hline 6) & $\begin{aligned} \ln \left(Y_{z 2, t}\right)= & -3.86-2.89 \times 10^{-2} \times L_{t-1}+6.35 \times 10^{-4} \times L_{t-1}^{2}-1.012 \times O_{m, t-4} \\
& +4.41 \times 10^{-2} \times\left(L_{t-1} \times P_{n, t-2}\right)\end{aligned}$ & 0.764 & 12.731 & $<2.20 \times 10^{-16}$ & -386 \\
\hline \multicolumn{6}{|c|}{ Zone 3} \\
\hline 7) & $\ln \left(Y_{z 3, t}\right)=-4.15-6.94 \times 10^{-3} \times L_{t-1}+0.983 \times O_{f, t-4}^{2}-2.38 \times \times 10^{-2} \times\left(L_{t-1} \times P_{f, t-2}\right)$ & 0.205 & 3.588 & $7.57 \times 10^{-4}$ & -410 \\
\hline 8) & $\ln \left(Y_{z 3, t}\right)=-4.19-7.00 \times 10^{-3} \times L_{t-1}-2.46 \times O_{f, t-4}^{3}+1.34 \times P_{f, t-2}^{2}$ & 0.190 & 3.429 & $1.22 \times 10^{-3}$ & -409 \\
\hline
\end{tabular}




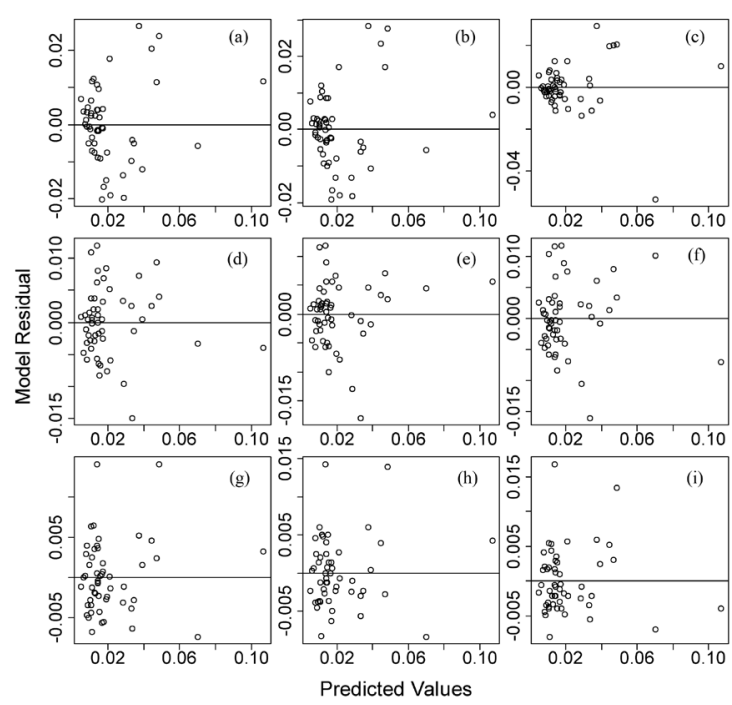

Figure 7. The residuals of models from Table 3 against the predicted values. The top panel is for Zone 1, middle panel for Zone 2 and the bottom panel for Zone 3. The roman numerals refer to the model numbers in Table 3 . The residual variance in all cases is $<0.09$.

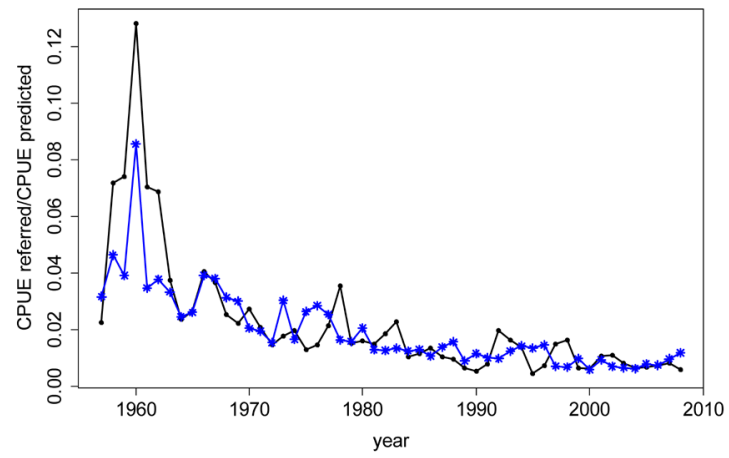

Figure 8. Graph showing the actual CPUE time series trajectory of the albacore tuna (T. alalunga) stock in Zone 1 in black and the trajectory which resulted from model i (Table 3) in blue for the years 1957-2008.

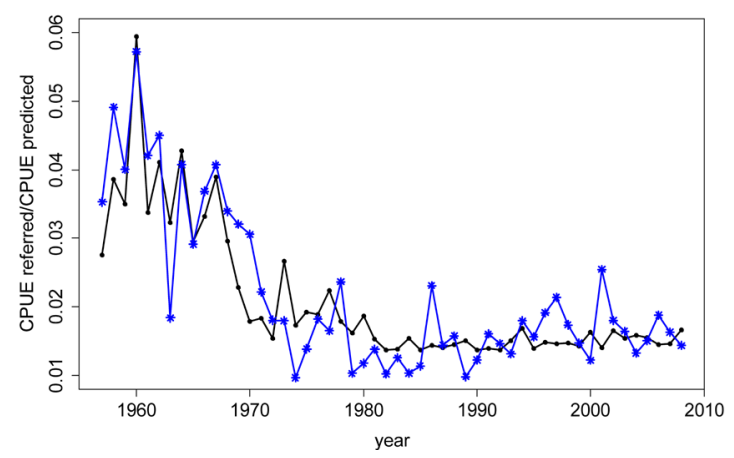

Figure 9. Graph showing the actual CPUE time series trajectory of the albacore tuna (T. alalunga) stock in Zone 2 in black and the trajectory which resulted from model iv (Table 3) in blue for the years 1957-2008. 


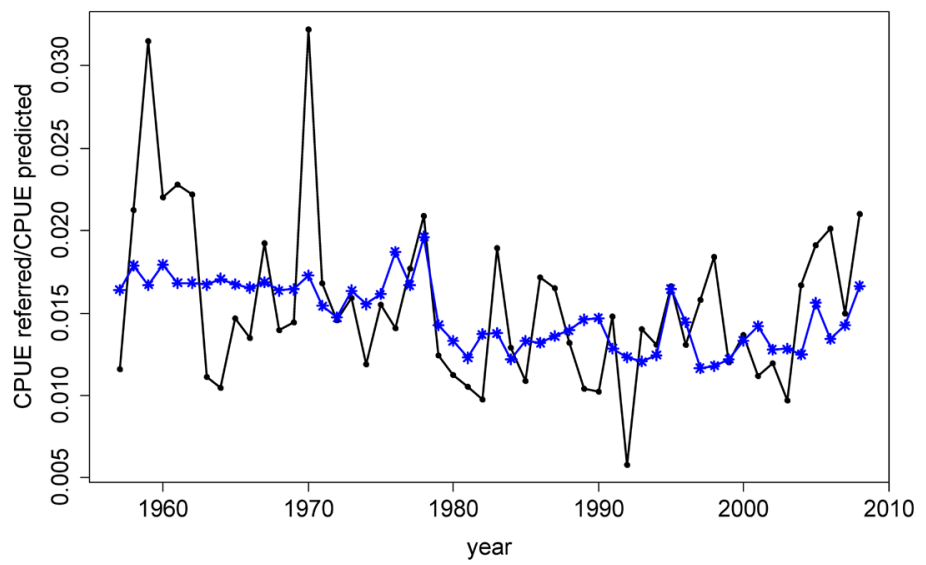

Figure 10. Graph showing the actual CPUE time series trajectory of the albacore tuna (T. alalunga) stock in Zone 3 in black and the trajectory which resulted from model vii (Table 3) in blue for the years 1957-2008.

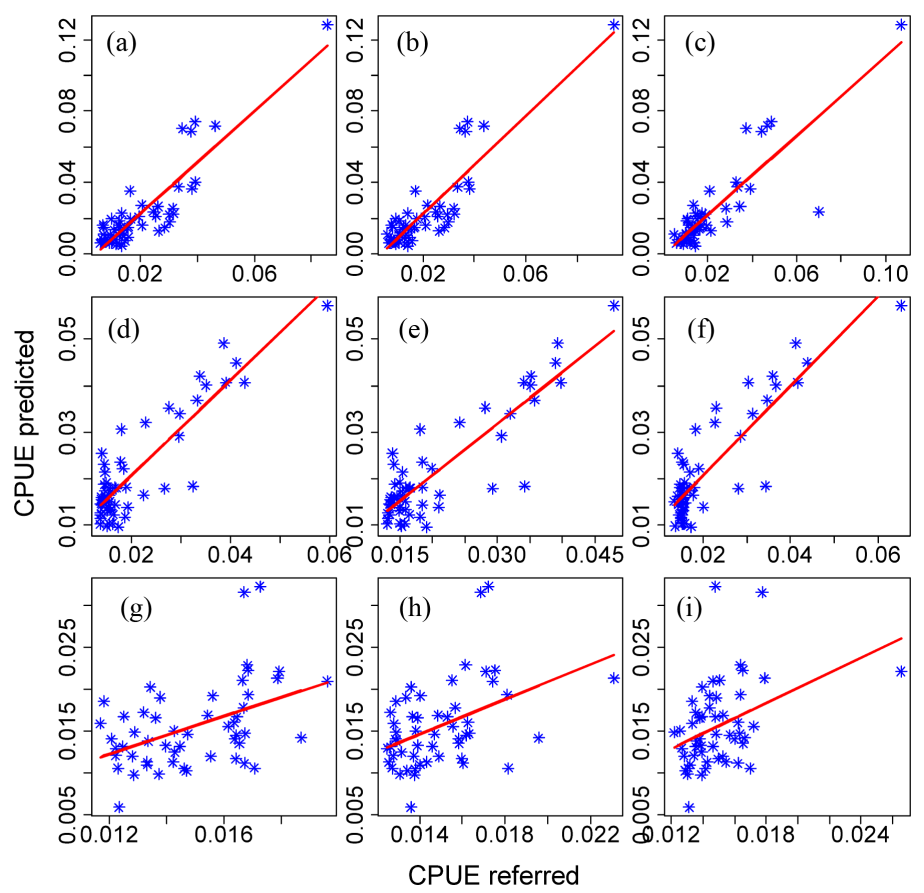

Figure 11. The linear relationship between the CPUE predicted and CPUE referred for the albacore tuna ( $T$. alalunga) stock in the South Pacific Ocean Zone 1 (top panel), Zone 2 (middle panel) and Zone 3 (bottom panel). The numbers refer to the model number presented in Table 3.

albacore tuna stock trajectory in the South Pacific Ocean.

The fluctuation patterns for the independent variables $L, P$ and $O$ time series which showed significant relationships with the dependent variables from Table 1 and resulted in statistically significant models for the albacore tuna in the South Pacific Zone 1, Zone 2 and Zone 3 from Table 3 are shown in Figure 12. LOTI exhibits a gradually increasing pattern from 1952 to 1977 from which point it fluctuates approximately parallel to the $\mathrm{x}$-axis up to 2008. PWI shows a gradual increasing pattern throughout the time series while PDO on average seems to run parallel to the $\mathrm{x}$-axis with different averages between 1952 to 1976 and 1977 to 2008. PDO is a climatic condition which is related to the climatic condition of Southern Oscillation Index (SOI) and El Niño and La Niña events. Indeed exploratory analysis showed the correlation of the PDO incorporated into the final 

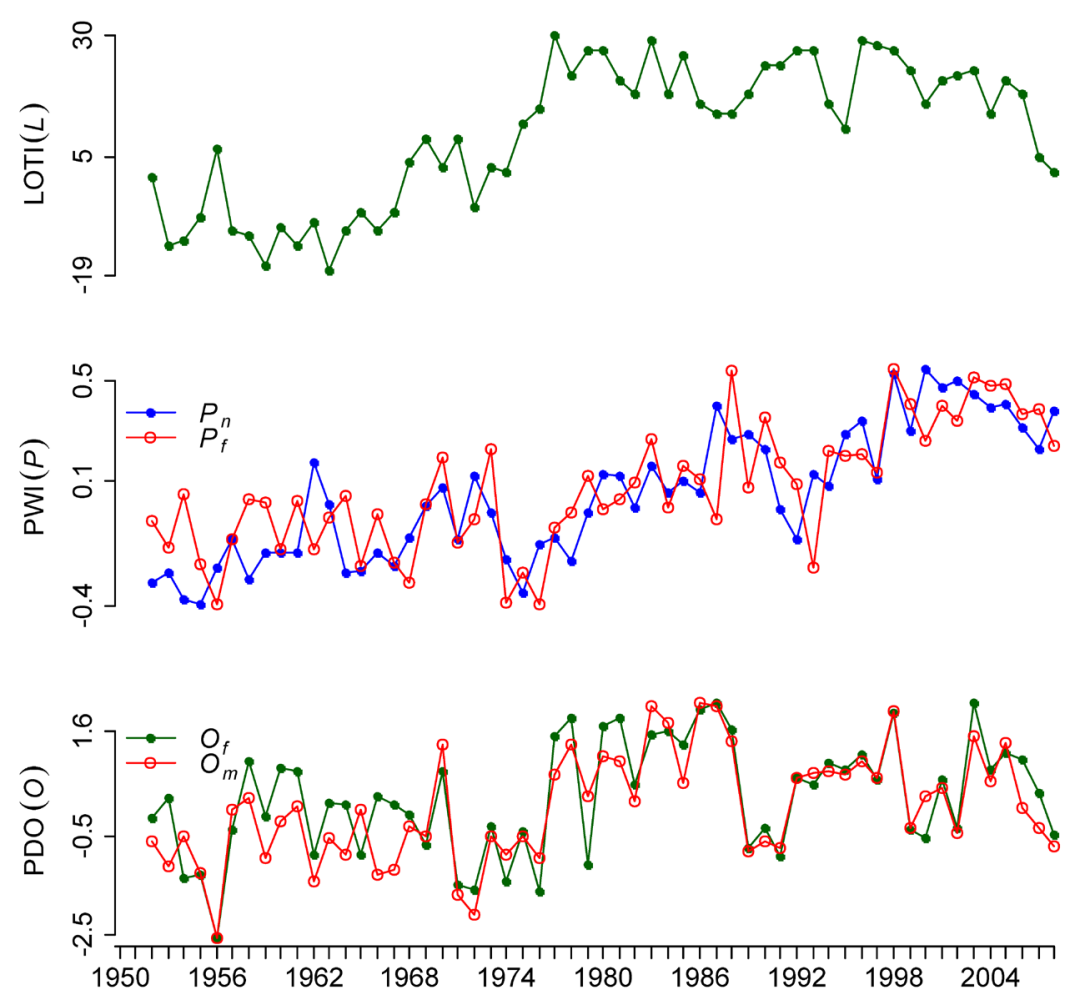

Figure 12. Time series pattern of the climatic conditions from 1952 to 2008. Graphs from top; the global mean land and ocean temperature index (LOTI) for the latitude band $44^{\circ} \mathrm{S}$ to $64^{\circ} \mathrm{S}(L)$, Pacific warm pool index (PWI) for the month of February $\left(P_{f}\right)$ and November $\left(P_{n}\right)$ and Pacific decadal oscillation (PDO) for the month of February $\left(O_{f}\right)$ and $\operatorname{March}\left(O_{m}\right)$.

models for albacore tuna in Zone 1, Zone 2 and Zone $3\left(O_{f}\right.$ and $\left.O_{m}\right)$ with SOI for the month of March and February and Niña 3 which is the Eastern Tropical Pacific sea surface temperature for the area $\left(5^{\circ} \mathrm{N}-5^{\circ} \mathrm{S}, 150^{\circ} \mathrm{W}\right.$ $90^{\circ} \mathrm{W}$ ) (Figure 13). From the three climatic conditions only PDO was used for modeling as it was the most significant among the three variables.

\section{Discussion}

This study was undertaken to determine the impact of climatic variables on the stock trajectory of the albacore tuna (T. alalunga) in the Eastern and Western South Pacific Ocean Zone 1, Zone 2 and Zone 3 (Figure 1). From Figure 2(a) and Figure 2(b) it can be seen that the CPUE in Zone 1 and Zone 2 was significantly higher in the early 1960s for Zone 1 and up to late 1960s for Zone 2 compared to the later decades where the CPUE has remained somewhat stable at lower levels. For Zone 3 (Figure 2(c)), the CPUE has more chaotic behavior in comparison to Zone 2 and Zone 3 but does not show significant change over the time series. From Figure 5 it can be observed that although the catch magnitudes among the three zones are quite different after the year 2000 the CPUE remains constant and synonymous which can be an indication that the stock levels in the South Pacific are still within sustainable limits which has also been stated in [21]. However, this does not guarantee sustainable albacore harvests for the future. From Figure 3 it can be observed that from the early 1990s the catch and effort have increased at an explosive rate for albacore tuna in all three zones. This behavior combined with the significant impact of the climatic conditions (Table 3) shown in this study poses a significant threat to the sustainability of the stock which can cause reduced CPUE of albacore tuna fishery where progressively higher efforts will be needed to maintain certain levels of catch which may not be economically viable leading to low supplies and higher prices of the catch.

We used CPUE for analysis in this study as it is a more suitable representative of albacore tuna stock time series compared to catch which we have shown to be significantly correlated to effort levels (Figure 4). For CPUE 

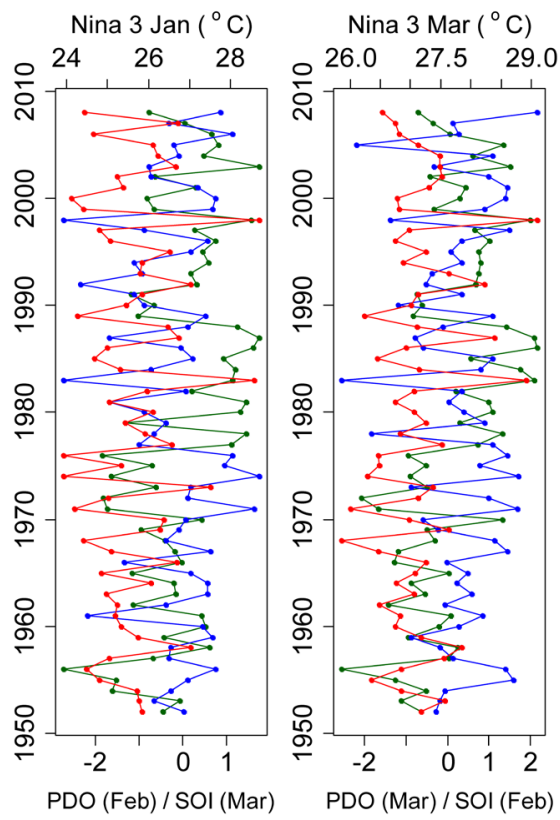

\begin{abstract}
Figure 13. Relationship of the PDO incorporated into the models for Zone $1\left(O_{f}\right)$, Zone $2\left(O_{m}\right)$ and Zone $3\left(O_{f}\right)$ (green line) with the climatic conditions of the Southern Oscillation Index (SOI) for the month of March and February (blue line) and Niña 3 (red line) which is the Eastern Tropical Pacific sea surface temperature for the area $\left(5^{\circ} \mathrm{N}-5^{\circ} \mathrm{S} 150^{\circ} \mathrm{W}-90^{\circ} \mathrm{W}\right)$ from $1952-2008$. PDO exhibits negative relationship with SOI and positive relationship with Niña 3. During negative PDO La Niña episodes dominate while El Niño events dominate during positive PDO. SOI and Niña 3 time series data were obtained from NOAA, Earth System Research Laboratory, Physical Sciences Division (http://www.esrl.noaa.gov).
\end{abstract}

the effort is standardized with the underlying assumption that the strength of each unit of effort remains constant over the time series which is reasonable as the effort for the time series utilized in this study has been recorded as the number of hooks. There can be some argument regarding this that even though the efforts are recorded as the number of hooks, technological development such as fish finders, better navigation, better hooks and lines might have increased the effort efficiency over time [37]. However, due to unavailability of such information we will accept the underlying assumption of albacore tuna effort for this study.

The results show that the climatic conditions of LOTI, PWI and PDO influence the albacore tuna stock trajectory in the South Pacific Zone 1, Zone 2 and Zone 3 and the models incorporating these variables exhibit significant fitness to the response variables (Table 3, Figures 8-10). LOTI is the index of the global land and sea surface air temperature for the latitude band from $44^{\circ} \mathrm{S}$ to $64^{\circ} \mathrm{S}(L)$ incorporated into the final models. This latitude band is of ecological significance as it cuts across and overlaps with the data coverage area; however its impact on albacore tuna stock is probably indirect in nature affecting intrinsic factors which more directly relate to the stock. LOTI has most significant fitness with albacore tuna stock trajectory in Zone 1, Zone 2 and Zone 3 with a lag of $t-1$ year (Table 3). Albacore tuna in the Pacific Ocean recruit to surface fisheries when they are about 2 years old and while age at catch ranges from 1 to 15 years, most of the stock is harvested when the stock is between 2 and 4 years old [23]-[25]. Ramon and Bailey [38] have shown that spawning by mature albacore tuna takes place in the South Pacific tropical and subtropical latitude band from $10^{\circ} \mathrm{S}$ to $25^{\circ} \mathrm{S}$ and the recruitment of the juveniles occurs after one year at around $40^{\circ} \mathrm{S}$ in New Zealand waters. Chen [39] showed that the SST, chlorophyll concentration and surface salinity requirement differed between the different developmental stages of the albacore tuna in the Indian Ocean from 1979 to 1985. From this it can be inferred that LOTI has indirect impact at the post-recruitment life stages of albacore tuna affecting factors such as prey stock levels, distribution as well as other factors relating to the ecological requirements of albacore tuna.

PWI is the water temperature index of a certain oceanic area in the Pacific Ocean which tends to be warmer than the rest of the ocean area. PWI for the month of November has most significant fitness with albacore tuna 
trajectory in Zone 1 and Zone 2 and in the month of February for Zone 3 with a lag of $t-2$ years in all three cases (Table 3). Zainuddin [40] studied the relationship of the albacore tuna catch data from 1998 to 2003 in the North Pacific Ocean $\left(30^{\circ} \mathrm{N}\right.$ to $\left.40^{\circ} \mathrm{N}\right)$ with sea surface temperature (SST) using remote sensing satellite images and chlorophyll-a concentration. Results showed that high albacore CPUE occurred in areas with high chlorophyll-a concentrations, which was related to warm SST, and catches were highest for the month of November from 1998 to 2003. Dufour [20] showed that the feeding migration of the offshore longitudinal distribution of albacore tuna in the Bay of Biscay was related to the warmer $17^{\circ} \mathrm{C}$ isotherm longitude from 1967 to 2005 . Farley [41] showed that the peak spawning of albacore tuna in the South Pacific Ocean occurred from October to December from the year 2006 to 2011. Tuna has been projected to relocate from the West of $170^{\circ} \mathrm{E}$ to the East of $170^{\circ} \mathrm{W}$ of the Pacific Ocean within the $21^{\text {st }}$ century following the more productive and preferred water temperatures of the Warm pool and Pacific Equatorial Divergence Province [1] [2] [15] [16] [42] [43]. PWI most likely affects the prey abundance and distribution as well as the spawning stages for the younger portion of the albacore tuna stock harvests in the South Pacific Ocean where major part of the harvested stock ranges from 2 to 4 years olds [23].

The PDO has been described as the El Niño like pattern of the North Pacific SST variability North of $20^{\circ} \mathrm{N}$ [44]-[46]. The effect of the PDO is spread Pacific wide where during the positive phase the South Pacific and central North Pacific gyres cool and the equatorial region and Eastern margin become warm and vice versa over decadal time scales [47]. Linsley [47] showed the strong association of the PDO with alterations in the upper oceanic heat of the South Pacific Ocean between $0.5^{\circ} \mathrm{S}-89.5^{\circ} \mathrm{S}$ and $64^{\circ} \mathrm{W}-147^{\circ} \mathrm{E}$ which falls within the albacore tuna distribution for Zone 1, Zone 2 and Zone 3 (Figure 1). Also, the spawning zone for the albacore tuna between $10^{\circ} \mathrm{S}$ and $25^{\circ} \mathrm{S}$ in the South Pacific Ocean is geolocated within the coverage area of Zone 1, Zone 2 and Zone 3 [38] [41]. Lehodey [48] showed a significant link between the changes in the Oceanic temperature and albacore tuna spawning in the Eastern and Western South Pacific between $5^{\circ} \mathrm{N}-55^{\circ} \mathrm{S}$ and $140^{\circ} \mathrm{E}-80^{\circ} \mathrm{W}$. PDO for the month of February fits most significantly with albacore tuna CPUE in Zone 1 and Zone 3 and in the month of March for Zone 2 with a lag of $t-4$ year for all three zones. Since most of the albacore tuna harvests in the Pacific Ocean are 2 - 4 years old [23], it can be assumed that PDO affects the spawning and early life stages of the albacore tuna in the Eastern and Western South Pacific Ocean. Lehodey [18] showed that the time series pattern for the South Pacific albacore tuna from the early 1960s to 2000 was related to the PDO time series trajectory. The relationship of El Niño and La Niña events and the related ENSO and SOI have been shown to be correlated to tuna stocks in the Pacific Oceans previously [12] [18] [19]. Indeed, exploratory analysis did show significant relationship between PDO, SOI and Niña 3 with El Niño events dominating during high Niña 3 SST and La Niña events dominating during low Niña 3 SST (Figure 13).

When comparing the correlation of the referred CPUE to the predicted CPUE for Zone 1, Zone 2 and Zone 3 from Figure 11, the slopes are either close to or not significantly different from unity, which accentuates that the climatic variables of LOTI, PWI and PDO incorporated into the models can reproduce a significant proportion of the albacore tuna stock trajectory in the three zones and that these climatic variables are responsible for a considerable portion of the fluctuation pattern of albacore tuna stock. The equation below represents the time series trajectory of albacore tuna in the South Pacific Zone 1, Zone 2 and Zone 3 written as

$$
Y_{z i, t}=b \cdot f\left(a_{1, t-n}, a_{2, t-n}, \cdots, a_{k, t-n}\right)
$$

where $Y_{z i, t}$ is the CPUE in the coverage zone zi with $i=1,2$ and 3, in year $t$ and $f()$ is the function determined by the abiotic climatic factors $a_{i}(i=1,2, \cdots, k)$ with a lag period of $n$ where $n=(0,1, \cdots, 5)$. Equation (3) shows the relationship which is followed for the albacore tuna stock through the climatic factors in the South Pacific Zone 1 , Zone 2 and Zone 3.

For albacore tuna in Zone 1 the fitted models with climatic condition of LOTI, PWI and PDO were most significant, followed closely by the fitted models for Zone 2 (Table 3 and Figure 11). For Zone 3, although the fitted models were significant, their fitness was much lower in comparison to Zone 1 and Zone 2 models. When we compare the relationship of the catch and effort from Figure 3 and Figure 4, it is noted that the relationship gets higher in significance from Zone 1 to Zone 2 with Zone 3 having the highest correlation. From Figure 4 and Figure 11 the further (closer) the points dispersing from the slope the higher (lower) the bias between the predicted and referred CPUE and the catch and effort relationship. From this phenomenon it can be stated that the better proportion of the albacore tuna time series trajectory for Zone 1 is influenced by the climatic conditions of LOTI, PWI and PDO followed closely by Zone 2 and at a much lower level by Zone 3. This harmonizes 
with the catch and effort relationship where the catch trajectory for Zone 3 is determined to a great extent by the effort followed by Zone 2 with the catch and effort relationship in Zone 1 being much lower in comparison to Zone 2 and Zone 3 . With this argument it can be said that the stock characteristics of albacore tuna in Zone 1 are markedly different from Zone 2 and Zone 3. As we move from the Eastern to the Western South Pacific Ocean the influence of LOTI, PWI and PDO on albacore tuna stock gets more prominent.

Tuna stocks in the tropical Pacific Ocean is presently seen as healthy; however continuous increase in fishing effort and harvest rates can present challenges for sustainable management [21] [49]. A common misconception in many fisheries management is that the stock trajectory of a fish is mainly due to the applied fishing pressure; however as the results of this study it shows that there may be a variety of biotic and abiotic factors acting together resulting in the stock dynamics of a fish species. Although fishing pressure probably does influence the stock trajectory of a given fishery, it should not be used as the only factor for the management of fisheries populations. Unavailability of data on various biotic and abiotic factors relating to the complex food web of tuna species in the Pacific Ocean poses challenges and creates gaps in knowledge [15] [16] for deducing and understanding the mechanisms by which climatic conditions affect these populations. In some cases the structure such as observer programs for collection of such data is already in place and offers an opportunity to collect such data as explained in [50]. For the albacore tuna stock in the Eastern and Western South Pacific Ocean Zone 1, Zone 2 and Zone 3, it is recommended that when management decisions are made for albacore tuna fishery in these areas, the influence of the climatic conditions of LOTI, PWI and PDO should be taken into consideration and further research should be directed at understanding the mechanism by which these climatic conditions influence the stock of albacore tuna for better management and sustainability of the fishery.

\section{Acknowledgements}

The authors extend their appreciation to the many research scientists, fishers and individuals who contributed towards the gathering of data on albacore tuna stock and climatic conditions of LOTI, PWI and PDO over the years. We also extend our gratitude to Swastika Roshni of the Ministry of Finance, Fiji, for assisting in sorting out large sets of albacore tuna stock data.

\section{References}

[1] Lehodey, P., Hampton, J., Brill, R.W., Nicol, S., Senina, I., Calmettes, B., Portner, H.O., Bopp, L., Ilyina, T., Bell, J.D. and Sibert, J. (2011) Vulnerability of Oceanic Fisheries in the Tropical Pacific to Climate Change. In: Bell, J.D., Jhonson, J.E. and Hobday, A.J., Eds., Vulnerability of Tropical Pacific Fisheries and Aquaculture to Climate Change, Secretariat of the Pacific Community, Noumea, 435-484.

[2] SPC (2012) Oceanic Fisheries and Climate Change. Secretariat of the Pacific Community, Policy Brief No. 15/2012.

[3] Bell, J.D., Kronen, M., Vunisea, A., Nash, W.J., Keeble, G., Demmke, A., Pontifex, S. and Andréfouët, S. (2009) Planning the Use of Fish for Food Security in the Pacific. Marine Policy, 33, 64-76. http://dx.doi.org/10.1016/j.marpol.2008.04.002

[4] Gillett, R. (2009) Fisheries in the Economics of Pacific Island Countries and Territories. Pacific Studies Series, Asian Development Bank, Manila.

[5] Collette, B. and Nauen, C. (1983) FAO Species Catalogue, Vol. 2. Scombrids of the World. An Annotated and Illustrated Catalogue of Tunas, Mackerels, Bonitos and Related Species Known to Date. FAO Fisheries Synopsis No. 125.

[6] Miyake, M.P., Miyabe, N. and Nakano, H. (2004) Historical Trends of Tuna Catches in the World. FAO Fisheries Technical Paper No. 467, Rome.

[7] ISSF. (2011) Status of the World Fisheries for Tuna: Management of Tuna Stocks and Fisheries. ISSF Technical Report 2011-05. International Seafood Sustainability Foundation, Virginia.

[8] Aaheim, A. and Signa, L. (2000) Economic Impacts of Climate Change on Tuna Fisheries in Fiji Islands and Kiribati. CICERO Report 2000:4, Center for International Climate and Environmental Research, Blindern.

[9] Amoe, J. (2005) Fiji Tuna and Billfish Fisheries. $1^{\text {st }}$ Meeting of the Scientific Committee of the Western and Central Pacific Fisheries Commission, Noumea, 8-19 August 2005, WCPFC-SCI, FR WP-12.

[10] Jones, J.B. (1991) Movements of Albacore Tuna (Thunnus alalunga) in the South Pacific_Evidence from Parasites. Marine Biology, 111, 1-9. http://dx.doi.org/10.1007/BF01986338

[11] Langley, A.D. and Hoyle, S.D. (2008) Report from the Stock Assessment Preparatory Workshop. No. WCPFC SC4 SA-IP-5, SPC, Noumea, February 2008. 
[12] Polovina, J.J., Howell, E., Kobayashi, D.R. and Seki, M.P. (2001) The Transition Zone Chlorophyll Front, a Dynamic Global Feature Defining Migration and Forage Habitat for Marine Resources. Progress in Oceanography, 49, 469-483. http://dx.doi.org/10.1016/S0079-6611(01)00036-2

[13] Harley, S., Williams, P., Nicol, S. and Hampton, J. (2011) The Western and Central Pacific Tuna Fishery: 2010 Overview and Status of Stocks. Tuna Fisheries Assessment Report No. 11, Secretariat of the Pacific Community, Noumea.

[14] Lehodey, P., Senina, I., Calmettes, B., Hampton, J. and Nicol, S. (2013) Modelling the Impact of Climate Change on Pacific Skipjack Tuna Population and Fisheries. Climate Change, 119, 95-109. http://dx.doi.org/10.1007/s10584-012-0595-1

[15] Le Borgne, R., Allain, V., Griffiths, S.P., Matear, R.J., McKinnon, A.D., Richardson, A.J. and Young, J.W. (2011) Vulnerability of Open Ocean Food Webs in the Tropical Pacific to Climate Change. In: Bell, J.D., Johnson, J.E. and Hobday, A.J., Eds., Vulnerability of Tropical Pacific Fisheries and Aquaculture to Climate Change, Secretariat of the Pacific Community, Noumea, 189-249.

[16] Ganachaud, A., Gupta, A.S., Brown, J.N., Evans, K., Maes, C., Muir, L.C. and Graham, F.S. (2013) Projected Changes in the Tropical Pacific Ocean of Importance to Tuna Fisheries. Climate Change, 119, 163-179. http://dx.doi.org/10.1007/s10584-012-0631-1

[17] Singh, A.A., Suzuki, N. and Sakuramoto, K. (2015) Influence of Climatic Conditions on the Time Series Fluctuation of Yellowfin Tuna Thunnus albacares in the South Pacific Ocean. Open Journal of Marine Science, 5, 247-264. http://dx.doi.org/10.4236/ojms.2015.53020

[18] Lehodey, P., Chai, F. and Hampton, J. (2003) Modelling Climate-Related Variability of Tuna Populations from a Coupled Ocean-Biogeochemical-Populations Dynamics Model. Fisheries Oceanography, 12, 483-494. http://dx.doi.org/10.1046/j.1365-2419.2003.00244.x

[19] Zainuddin, M., Saitoh, S. and Saitoh, K. (2004) Detection of Potential Fishing Ground for Albacore Tuna Using Synoptic Measurements of Ocean Colour and Thermal Remote Sensing in the Northwestern North Pacific. Geophysical Research Letters, 31, Article ID: L20311. http://dx.doi.org/10.1029/2004gl021000

[20] Dufour, F., Arrizabalaga, H., Irigoien, X. and Santiago, J. (2010) Climate Impacts on Albacore and Bluefin Tunas Migrations Phenology and Spatial Distribution. Progress in Oceanography, 86, 283-290. http://dx.doi.org/10.1016/j.pocean.2010.04.007

[21] SPC (2012) The Western and Central Pacific tuna Fishery: 2010 Overview and Status of Stocks. Policy Brief No. 14/2012, Secretariat of the Pacific Community, Noumea.

[22] Hansen. J., Ruedy, R., Sato, M. and Lo, K. (2010) Global Surface Temperature Change. Reviews of Geophysics, 48, 129. http://dx.doi.org/10.1029/2010RG000345

[23] ALBWG (2011) Stock Assessment of Albacore Tuna in the North Pacific Ocean in 2011. In: Report of the Albacore Working Group Stock Assessment Workshop, Shizuoka, 4-11 June 2011, 10-18.

[24] Wells, R.D., Kohin, S., Teo, S.L., Snodgrass, O.E. and Uosaki, K. (2013) Age and Growth of North Pacific Albacore (Thunnus alalunga): Implications for Stock Assessment. Fisheries Research, 147, 55-62. http://dx.doi.org/10.1016/j.fishres.2013.05.001

[25] Chen, K.S., Shimose, T., Tanabe, T., Chen, C.Y. and Hsu, C.C. (2012) Age and Growth of Albacore Thunnus alalunga in the North Pacific Ocean. Journal of Fish Biology, 80, 2328-2344. http://dx.doi.org/10.1111/j.1095-8649.2012.03292.x

[26] Zurr, A.F., Leno, E.N. and Elphick, C.S. (2010) A Protocol for Data Exploration to Avoid Common Statistical Problems. Methods in Ecology and Evolution, 1, 3-14. http://dx.doi.org/10.1111/j.2041-210X.2009.00001.X

[27] Dickey, D.A. and Fuller, W.A. (1979) Distribution of the Estimators for Autoregressive Time Series with a Unit Root. Journal of the American Statistical Association, 74, 427-431. http://dx.doi.org/10.2307/2286348

[28] Kwiatkowski, D., Phillips, P.C.B., Schmidt, P. and Shin, Y. (1992) Testing the Null Hypothesis of Stationarity against the Alternative of a Unit Root. Journal of Econometrics, 54, 159-178. http://dx.doi.org/10.1016/0304-4076(92)90104-Y

[29] MacKinnon, J.G. (1996) Numerical Distribution Functions for Unit Root and Cointegration Tests. Journal of Applied Econometrics, 11, 601-618. http://dx.doi.org/10.1002/(SICI)1099-1255(199611)11:6\%3C601::AID-JAE417\%3E3.0.CO;2-T

[30] Myers, R.H., Montgomery, D.C. and Anderson-Cook, C.M. (2009) Response Surface Methodology: Process and Product Optimization Using Designed Experiments. John Wiley and Sons, Hoboken.

[31] Buchanan, R.L. and Phillips, J.G. (1990) Response Surface Model for Predicting the Effects of Temperature, pH, Sodium Chloride Content, Sodium Nitrate Concentration and Atmosphere on the Growth of Listeria monocytogenes. Journal of Food Protection, 53, 370-381. 
[32] Bezerra, M.A., Santelli, R.E., Oliveira, E.P., Villar, L.S. and Escaleira, L.A. (2008) Response Surface Methodology as a Tool for Optimization in Analytical Chemistry. Talanta, 76, 965-977. http://dx.doi.org/10.1016/j.talanta.2008.05.019

[33] Box, G.E. and Behnken, D.W. (1960) Some New Three Level Designs for the Study of Quantitative Variables. Technometrics, 2, 455-475. http://dx.doi.org/10.1080/00401706.1960.10489912

[34] Fox, J. (2008) Applied Regression Analysis and Generalized Linear Models. 2nd Edition, Sage Publications, Thousand Oaks.

[35] Akaike, H. (1981) Likelihood of a Model and Information Criteria. Journal of Econometrics, 16, 3-14. http://dx.doi.org/10.1016/0304-4076(81)90071-3

[36] R Core Team (2014) R: A Language and Environment for Statistical Computing. R Foundation for Statistical Computing, Vienna. http://www.r-project.org/

[37] Bigelow, K.A., Hampton, J. and Miyabe, N. (2002) Application of a Habitat-Based Model to Estimate the Effective Longline Fishing Effort and Relative Abundance of Pacific Bigeye Tuna (Thunnus obesus). Fisheries Oceanography, 11, 143-155. http://dx.doi.org/10.1046/j.1365-2419.2002.00196.x

[38] Ramon, D. and Bailey, K. (1996) Spawning Seasonality of Albacore, Thunnus alalunga, in the South Pacific Ocean. Fishery Bulletin, 94, 725-733.

[39] Chen, I., Lee, P. and Tzeng, W. (2005) Distribution of Albacore (Thunnus alalunga) in the Indian Ocean and Its Relation to Environmental Factors. Fisheries Oceanography, 14, 71-80. http://dx.doi.org/10.1111/j.1365-2419.2004.00322.x

[40] Zainuddin, M., Kiyofuji, H., Saitoh, K. and Saitoh, S. (2006) Using Multi-Sensor Satellite Remote Sensing and Catch Data to Detect Ocean Hot Spots for Albacore (Thunnus alalunga) in the Northwestern North Pacific. Deep-Sea Research II, 53, 419-431. http://dx.doi.org/10.1016/j.dsr2.2006.01.007

[41] Farley, J.H., Williams, A.J., Hoyle, S.D., Davies, C.R. and Nicol, S.J. (2012) Reproductive Dynamics and Potential Annual Fecundity of South Pacific Albacore Tuna (Thunnus alalunga). PLoS ONE, 8, e60577. http://dx.doi.org/10.1371/journal.pone.0060577

[42] Bell, J.D., Reid, C., Batty, M.J., Lehodey, P., Rodwell, L., Hobday, A.J., Johnson, J.E. and Demmke, A. (2013) Effects of Climate Change on Oceanic Fisheries in the Tropical Pacific: Implications for Economic Development and Food Security. Climate Change, 119, 199-212. http://dx.doi.org/10.1007/s10584-012-0606-2

[43] Ganachaud, A., Gupta, A.S., Orr, J.C., Wijffels, S.E., Ridgway, K.R., Hemer, M.A., Maes, C., Steinberg, C.R., Tribollet, A.D., Qiu, B. and Kruger, J.C. (2011) Observed and Expected Changes in the Tropical Pacific Ocean. In: Bell, J.D., Johnson, J.E. and Hobday, A.J., Eds., Vulnerability of Tropical Pacific Fisheries and Aquaculture to Climate Change, Secretariat of the Pacific Community, Noumea, 101-187.

[44] Zhang, Y., Wallace, J.M. and Battisti, D.S. (1997) ENSO-Like Interdecadal Variability: 1900-93. Journal of Climate, 10, 1004-1020. http://dx.doi.org/10.1175/1520-0442(1997)010\%3C1004:ELIV\%3E2.0.CO;2

[45] Mantua, N.J., Hare, S.R., Zhang, Y., Wallace, J.M. and Francis, R.C. (1997) A Pacific Interdecadal Climate Oscillation with Impacts on Salmon Production. Bulletin of the American Meteorological Society, 78, 1069-1079. http://dx.doi.org/10.1175/1520-0477(1997)078\%3C1069:APICOW\%3E2.0.CO;2

[46] Deser, C., Phillips, A.S. and Hurrell, J.W. (2004) Pacific Interdecadal Climate Variability: Linkages between the Tropics and the North Pacific during Boreal Winter since 1900. Journal of Climate, 17, 3109-3124. http://dx.doi.org/10.1175/1520-0442(2004)017\%3C3109:PICVLB\%3E2.0.CO;2

[47] Linsley, B.K., Wu, H.C., Dassié, E.P. and Schrag, D.P. (2015) Decadal Changes in South Pacific Sea Surface Temperatures and the Relationship to the Pacific Decadal Oscillation and Upper Ocean Heat Content. Geophysical Research Letters, 42, 2358-2366. http://dx.doi.org/10.1002/2015GL063045

[48] Lehodey, P., Senina, I., Nicol, S. and Hampton, J. (2015) Modelling the Impact of Climate Change on South Pacific Albacore Tuna. Deep Sea Research Part II: Tropical Studies in Oceanography, 113, 246-259. http://dx.doi.org/10.1016/j.dsr2.2014.10.028

[49] Rice, J. and Garcia, S. (2011) Fisheries, Food Security, Climate Change and Biodiversity: Characteristics of the Sector and Perspectives on Emerging Issues. ICES Journal of Marine Science, 68, 1343-1353. http://dx.doi.org/10.1093/icesjms/fsr041

[50] Nicol, S.J., Allain, V., Pilling, G.M., Polovina, J., Coll, M., Bell, J., Dalzell, P., Sharples, P., Olson, R., Griffiths, S., Dambacher, J.M., Young, J., Lewis, A., Hampton, J., Molina, J.J., Hoyle, S., Briand, K., Bax, N., Lehodey, P. and Williams, P. (2013) An Ocean Observation System for Monitoring the Effects of Climate Change on the Ecology and Sustainability of Pelagic Fisheries in the Pacific Ocean. Climate Change, 119, 131-145. http://dx.doi.org/10.1007/s10584-012-0598-y 